\title{
Development of a Trauma-based Continuing Care Model for Enhancing Care Outcomes in Social Unrest Area: A Case Study
}

\section{Praneed Songwathana $^{1^{*}}$, Wipa Sae-Sia ${ }^{2}$, Luppana Kitrungrote ${ }^{2}$ and Benjawan Manoonya ${ }^{3}$}

${ }^{1}$ Associate Professor, Faculty of Nursing, Prince of Songkla University, Hatyai, Songkhla, Thailand.

${ }^{2}$ Assistant Professor, Faculty of Nursing, Prince of Songkla University, Hatyai, Songkhla, Thailand.

${ }^{3}$ Advance Practice Nurse, Narathiwat Rachanagarind Hospital, Narathiwat, Thailand.

"Corresponding author: Praneed Songwatahna, Associate Professor, Faculty of Nursing, Prince of Songkla University, Hatyai, Songkhla, Thailand, Tel: 66-74-286518; E-mail: spraneed@yahoo.com

Received date: June 10, 2014, Accepted date: September 16, 2014, Published date: September 19, 2014

Copyright: (c) 2014 Songwathana P. This is an open-access article distributed under the terms of the Creative Commons Attribution License, which permits unrestricted use, distribution, and reproduction in any medium, provided the original author and source are credited.

\begin{abstract}
Background: Improving care outcomes in trauma patients is regarded as important and linked to an appropriate model of care particularly in social unrest area where there are limited resources and accessibility after discharge. To facilitate prompt management to improve patient recovery or quality of life and decrease some complications, a specific model of continuing care for those trauma survivors is required.
\end{abstract}

Objective: This participatory action research (PAR) aimed to develop the trauma-based continuing care model (TCCM) for enhancing care outcomes in trauma patients affected from Social Unrest area.

Method: A three-phase of PAR design was implemented with stakeholders in both hospital and community services related to care for trauma survivors and their families. In the first phase, 11 trauma survivors were interviewed and 3 focus group discussions with nurses and related health care staff were conducted to identify existing systems and problems encountered. The second phase consisted of two workshops, involving 20 key informants and allied health staff for the purpose of developing the model. The final phase evaluated the initial effects of the model after implementing with 20 patients by measuring the care process and outcomes such as nurses'satisfaction, patients'quality of life, patients'self care ability, caregivers' ability to care. Data were analyzed using descriptive statistics for care outcomes and content analysis for the care process.

Result: The model consisted of a) trauma-care process through a trauma nurse-initiated discharge planning program b) patient-family follow up. With the PAR process, the following steps included 1) preparing the multidisciplinary health care team including patient and family caregivers, 2) organizing the system, identifying individual role and function for continuing care, and 3) collaborating with community support network for patient and family management. The main strategies to drive all process were teamwork involvement, care coordination, and staff education.

The model could enhance both health care staff and family caregivers in providing better care. In this study, most patients were able to manage themselves. Twenty patients and 10 family caregivers were satisfied with the care process and obtained better outcomes regarding health status and quality of life. In addition, the developed trauma nurse-initiated discharge planning program was also discussed for further implication.

Conclusion: The key success was derived from trauma nurse-initiated discharge planning process and collaborating with community support network. To enhance the sustainability of the model, care managed by enhancing networking of community nurse, patient and family after discharge needs to be further explored.

\section{Keywords: Trauma care; Care outcomes; Social unrest}

\section{Background}

The scope of trauma care has been shift from hospital-based to a system approach which includes the global care of injured patient, from time of injury to the end of rehabilitation [1]. This can alert many communities and hospital care systems to recognize the need of continuing care in order to utilize available resources to the most effective and costless including reduce trauma morbidity and mortality $[2]$.
The concept of continuing care has been linked with quality of life. Continuing of care is a major goal of nursing practice and the main objective of discharge planning protocols, especially with release of patients from hospital being quicker and sicker [3]. Nurses currently recognize the importance of continuing care model for trauma patients in their practice. Their practice is predominantly centered on measuring care outcomes, often without considering the experience of those directly and indirectly affected by the trauma in social unrest area where there is limited availability of resources.

In recent decades, the epidemiological studies in Thailand as elsewhere in developing countries have indicated an increase in the 
rates of mortality, morbidity and disability caused by trauma, not only due to road traffic accident but also from human terrorists, which configures it as a serious social problem. There are also serious economic repercussions, since this can not only impair the working capacity of the victims, but also leads to high cost for rehabilitation due to its resulting temporary or permanent disability. Furthermore, significant physical, mental and cognitive deficits, with impairment in the quality of life of victims and their families are among the possible damage caused by trauma.

In addition, as a paradigm shift from a dependent functioning affected by trauma to an independent functioning, improved care outcomes when trauma patients received holistic treatment and care are then emphasized. However, ways to improve patient outcomes are remained unexplored in unrest areas where less accessibility to available resources. In order to enhance care outcomes of trauma in the social unrest setting, developing a continuing care model is expected. Previous nursing studies have shown that the process of participatory action research (PAR) gives power to study participants by allowing them to construct and use their own knowledge, as well as produce knowledge and useful action for them to implement sustained changes in the structure of an existing system [4,5]. Hence, PAR was conducted in this study aimed to answer the research questions: 1) what are the components of continuing care model for enhancing the QOL of trauma survivors in the Thai social unrest community 2) what are the care process and outcomes after implementing the model?

\section{Conceptual Framework}

The conceptual framework was based on the concept of comprehensive trauma care system and holistic approach to provide cost-effective services for patient care. The center of this system is continuum of care which starts from injury prevention to posthospital care or discharge. Continuum of care is a coherent health care with a seamless transition over time between various providers in different settings [6]. In addition, caring within a holistic approach could guide an intervention to improve quality of care. PAR (participatory action research) was used as an approach of model development which involved 5 spiral steps including assessing, planning a change, acting and observing, reflecting and re-planning [7]. These steps were used to guide the process and outcomes of trauma continuing care. In this study, the care outcomes measured included care process (care team management) and care outcomes (such as patients' self care and quality of life, families' ability to care, nurses' satisfaction to the model).

\section{Research aim}

The study was aimed to 1) develop a continuing care model for enhancing the QOL of trauma survivors in the Thai social unrest community, and 2) evaluate the initially care outcomes after implementing the model.

\section{Method}

A three-phase of PAR design was conducted over 12 months, comprising 2 months for phase 1 (situational analysis), 5 months for phase 2 (model development), and 3 months for phase 3 (evaluation).

Phase 1: Situational analysis. This phase involved examining the existing trauma care system context and patient experiences after discharge. Three focus group discussions with nurses and related health care staff were conducted to identify the existing system and problems encountered. In-depth interviews were conducted with 11 trauma survivors who were discharged and lived at home (from previous project) to explore their problems and needs of holistic care in daily living.

Phase 2: Model development. The PAR process was conducted with the involvement of 20 stakeholders throughout. Two workshops were performed to formulate the tentative plan, care process and intervention, including follow-up method. Maintenance of continuity of care for trauma patients in the community was also performed by the last author, in coordination with a community/primary health care team during implementation of the model. The last author assumed the role of facilitator or coordinator for the purpose of obtaining suggestions, directions, and support from other health care providers, such as mental health nurses, physiatrists, physical therapists, occupational therapists, or social workers. In addition, the researcher implemented the process of action research with the participants until an acceptable model of care for enhancing the care outcome of trauma patients in social unrest area evolved.

Initially, the tentative care model was developed from review of the literature, qualitative data analysis from the reconnaissance phase of the study, and suggestions made by three nursing administrators and two experienced nurses. Secondly, a pilot study was conducted with two cases. Thirdly, for model verification, the researcher introduced the tentative care model from pilot study to the trauma care team, which included orthopedic nurses, physiatrists, physiotherapists and occupational therapists, and asked for their suggestions. Fourthly, a focus group of the trauma staff nurses was conducted to develop a tentative care model for enhancing the care outcomes (quality of life) of trauma patients after discharge. Lastly, several tentative interventions were designed to be congruent with their socio-cultural background.

Phase 3: Evaluation. The final phase aimed to evaluate some care outcomes such as patient quality of life, patients' self care ability, caregivers' ability to care on the discharge day and after discharge. Participants in phase 2 and 3 included trauma patient and family caregivers who were admitted at hospital as a result from terrorist activity. A reflection guide related to the model was developed by the researcher for the purpose of allowing participants to reflect on the care process, the model components, and model implementation.

\section{Setting}

The study was held at one of the general hospitals in 3 southern Thai provinces. It has 400 beds with 14 inpatient units. Four of them namely male orthopedic ward, female surgical ward, respiratory care unit and pediatric ward were commonly occupied with trauma patients affected from terrorisms. Some patients were also allocated to other special units depending on the number of admissions and patient needs. The ratio of nurse to patient in each ward was about 1 to 6-8.

\section{Ethical considerations}

Approval to conduct the study was granted by the ethics review board of the hospital. Participants in all phases were informed about the purpose and process of the study, and of their right to discontinue from the study at any time without any negative consequences. Verbal consent to take part in the phase 2 and 3 was obtained from 20 stakeholders (12 nurses from 4 main wards, 2 psychologists, 2 social 
workers, 2 occupational therapists, 1 community health nurse, 1 community volunteer leader from a non-profit organization who visited and provided care at home for 20 patients and 10 family caregivers.

\section{Results}

The results are presented following the three phases of the study.

\section{Phase 1 Process of model development of the continuing care}

This part will describe the process of model development based on PAR, presented as follows.

Reconnaissance phase: Understanding existing care system context and patient experiences after discharge.

Data gathered from in-depth interviews of the 11 trauma survivors who lived at home revealed the need of holistic care in daily living. Results show the common experiences after discharge as to be learning to have a new life, and bearing with the increased care demands of a chronic disease [6]. The main health problems were both physical and psychological and required continuing care after discharge. These included: 1) changing physical conditions, such as limited movement, suffering from pain and recurrence of pressure sore and urinary infection; 2) suffering, such as why it happened to me, feeling upset at being unable to do things and thinking too much /having delusion/ experiencing sleeplessness; and 3) living with hardship and paranoid.

Due to multiple organ injury and complexity of injury, continuing care is required from emergency phase to recovery phase. The focus group of nurses also identified that the existing care system still lacked comprehensive discharge planning and care coordination both intra and inter-unit in and out of hospital. Incomplete information and documentation during the transitional period was recognized and the care system after discharge was separated from hospitalization, which affected quality of care. In addition, discharge preparedness program was not performed as needed. Some patients returned to hospital with the recurrent problems, as a nurse reflected "some patients were admitted in hospital for a long time partly due to inability to care for self, as a result, patient often returned with the preventable recurrent problems". The home visit program was also managed without a systematic plan; it just depends on individual rather teamwork. Lack of coordination and communication of patient problems and caring needs related to discharge plan and inconsistent follow up including no outcomes measure were identified. In summary, three main issues related to discharge planning that required further development in phase 2 was 1) lack of care coordination between each unit with unclear discharge program 2) incomplete system of follow up after discharge and lack of multidisciplinary team 3) no care manager/ discharge planner.

Training phase : Two workshops were organized that aimed 1) to increase the stakeholders' awareness and knowledge about continuing care process, problems and issues related to trauma patient management, 2) to initiate a trauma nurse-initiated discharge planning model that involved all stakeholders. The groups in the workshop consisted of 12 nurses from 4 main wards, 2 psychologists, 2 social workers, 2 occupational therapists, 1 community health nurse, and 1 community volunteer leader from non-profit organization.

During the first workshop, a tentative model of continuing care integrated with nursing process for enhancing care outcomes was established (Figure1). Strategies to improve patient quality of life, patient's self care ability, caregivers' ability to care were discussed and organized into the model. The second workshop was held with 10 nurse leaders who utilized PAR to improve the role and function of the team approach and care coordination. At this phase, trauma nurseinitiated discharge plan and having trauma nurse coordinator were emphasized in the tentative model as it was given a priority by stakeholders.

In addition, a study visit at another hospital was conducted aimed exchanging and sharing of discharge planning strategies, and education sessions were provided for patients and caregivers and the tentative model discussed. To ensure the feasibility of the model, two cases were conducted. It was found that the care process must be revised and started earlier including required modification of the model to fit with the hospital context of care. As a result, nurses suggested integrating with usual care by using a care map to guide nursing activities throughout hospitalization and after discharge.

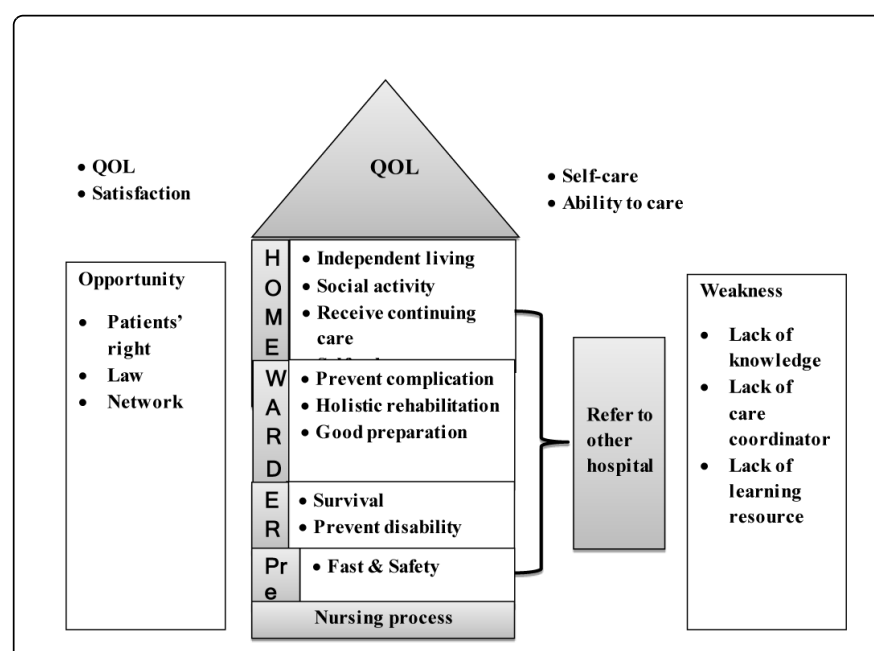

Figure 1: Tentative model of trauma based continuing care in social unrest area.

After implementing a model with two cases, some problems were found related to the care system. Due to difficulty in managing many activities at the same time as well as the complexity of injury (more than one organ system injured), care activities were integrated into a patient care map starting from admission and continuing to discharge. After learning from the study visit, care management was introduced and modified to fit with the setting by assignment of at least two nurses for managing the trauma discharge planning program. Nurses and others in the multidisciplinary team worked together under each role and were satisfied with the care system. However, the care map was revised again in terms of follow up plan for mild injury patients due to earlier discharge. As a nurse reflected "the care map was helpful and clear for the team to use for nursing practice except for mild injury cases due to short stay".

Upon completion of the workshop, the nurses and core leaders $(n=10)$ who continued to join the study visit and participate in the last phase of the study provided addition information to refine the model. Three main types of nursing system management were added to enhance the care outcomes. They include 1) creating a quality of continuing care management system based on a multidisciplinary teamwork identified as a successful management system 2) providing patients both physical and psychological care through discharge 3) 
educating patients to be able to take care of themselves as well as educating caregiver to have its capability to care to reduce or prevent complications. Following the model development, the researchers confirmed the accuracy of the model with the 10 nurses who participated throughout the study. In addition, knowledge on clinical practice guideline (CPG) for prevention and reduction of patient's risk, such as pain management, wound care, promoting nutrition in trauma, and identify nurse' role as well as multidisciplinary team was taught.

Nursing care management system for enhancing continuing care was set up by integrating the new trauma-based discharge planning program consisting of care management process (9 steps) and DMETHOD (see Figure 2). In order to implement trauma-based discharge planning program (TDPP), workshops and new approach based on evidence based knowledge related to trauma care were organized. Multidisciplinary team approach was emphasized for the purpose of developing more confidence of their role and responsibility in providing both physical and psychological care together.

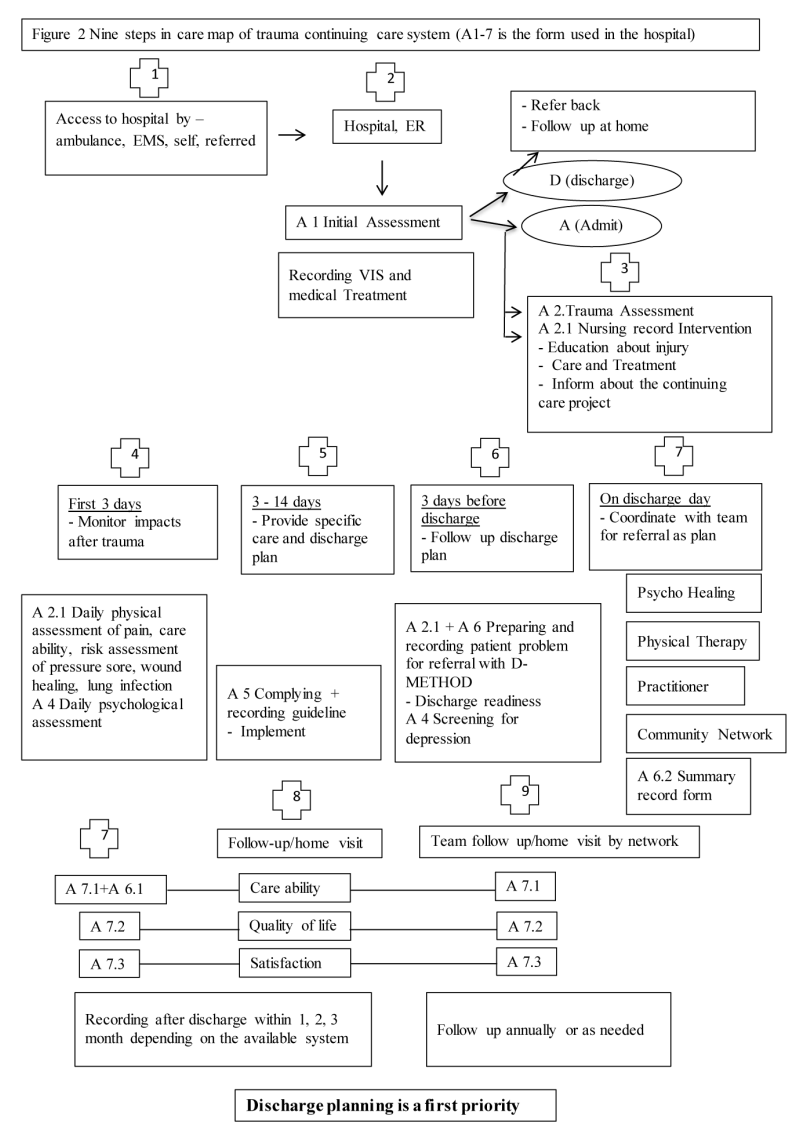

Figure 2 : Nine steps in care map of trauma continuing care system (A1-7 is the form used in the hospital).

A Trauma-based Continuing Care Model (TCCM) was developed based on nursing care process and trauma nursing as the conceptual framework and analysis of qualitative data and synthesis of the activities that had occurred in the PAR process (see Figure 3). The TCCM consists of a) trauma care process through a trauma nurse- initiated discharge planning program, and b) patient-family management process. With the PAR process, the following steps included 1) preparing the multidisciplinary health care team including patient and family caregivers, 2) organizing the system, individual role and function for continuing care, and 3) collaborating with support network for patient and family. Under the PAR process, the important application used throughout the study was facilitating participants to look, think and act together based on the Stringer [7]. As the role of facilitator in PAR, several activities and outcomes learned from individual and group experiences were described in the model.

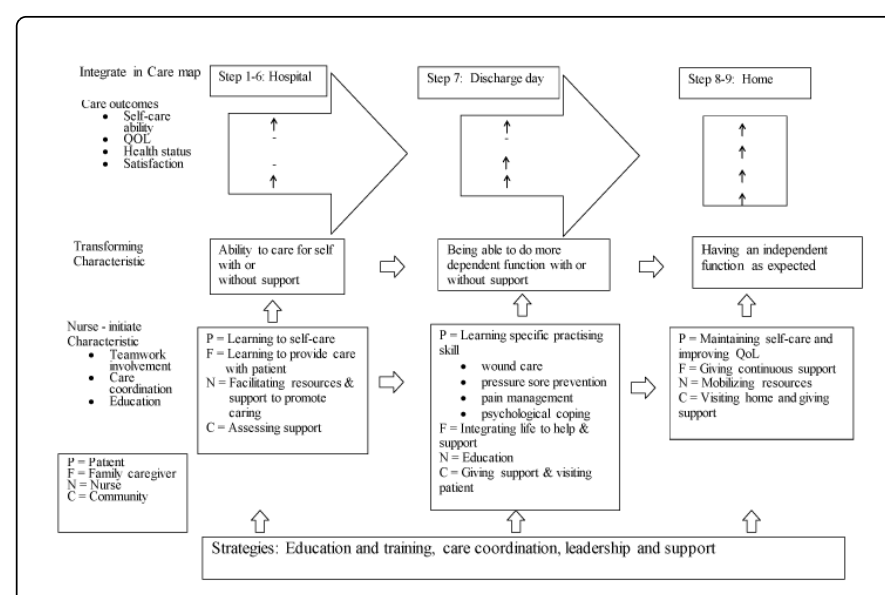

Figure 3 : Trauma- based continuing care model for enhancing care outcomes in social unrest.

\section{Phase 2 Model implementation}

Based on the analysis of PAR process and qualitative data from workshops and 20 patients who were taken care after implanting the model, the trauma nurse-initiated discharge planning program was the most important strategy for enhancing care outcomes before and after discharge.

In this study, psychologist and occupational therapist are important in the model as they are able to accompany the team to follow up patients after discharge. The main issues in caring for this patient group identified by team were: 1) unclear information about patient right to receive support from several organizations, 2) no system of report after discharge or referral back home between hospital and community. Patients may be delayed in early detection and receiving proper treatment as most complications are preventable. The core team reflected their lesson learnt with researchers and suggested a strategic plan and activities via education and training, care coordination, leadership and support as follows.

- Develop a multidisciplinary team documentation for continuing care by integrating it with an existing form (care map) and make it in a simple format of recording to review all patient care. The continuing care process was described as a guide in one page.

- Identify overall goal of trauma-based discharge plan and specific plan for individual problems, including assigning a definite role of discharge planner and allocating a few nurses in a discharge plan team under the head nurse' supervision.

- Appropriate assessment tools were selected and used for outcome evaluation. These included patient's self care ability, family's ability to care, satisfaction and quality of life. 
- Develop a teaching program and home care package for family caregivers. The teaching program was integrated into the TCCM.

- Identify follow-up plan and have the home visit team collaborate with community resources and networks

- Hold capacity-building sessions for nurses and allied health team in both general and community hospitals which are under the continuing care network at the provincial level. Various topics were organized for trauma assessment and care in the social unrest area such as continuing care management in multiple trauma patient, trauma pain management, wound care management, principle of discharge planning and its application in trauma care, documentation and reporting system in trauma based continuing care, patient care management in transitional process including quality of trauma care and care outcomes evaluation.

\section{Phase 3 Evaluation of model implementation and care outcomes}

The model was revised according to the above comments and implemented again throughout the patient journey from admission to discharge. Some changes were found as follows:

- The care coordination team between hospital and community sector was established by including a coordinator of the community volunteers to be a member of the core team as well as of the multidisciplinary team. A system of discharge planning including home visiting program under the multidisciplinary team was setup to facilitate the continuing care for trauma patients. The system plays a role in informing and motivating patients in self care and family caregivers in caring for patients in a holistic way after discharge. Additionally, the discharge planner or leader was able to follow up and monitor patients and families'ability to care before and after discharge. She serves as a trauma nurse coordinator who was able to use her expertise to develop better educational plans for patients and families.

- In the PAR process, 3 main strategies were used in the model which interacted via education and training, care coordination, leadership and support as above throughout the end of model as shown in Figure 3.

\section{Evaluation of the care process}

Nine steps of care process were developed to guide the nurses for improving the continuing care (Figure 2). The first three steps were started at the emergency department or other units such as intensive care unit before the patient was transferred to ward based on patient's condition. Generally, patients were admitted at ward directly except those who required emergency operation or were critically ill or were refereed to other tertiary hospitals for proper management as needed. For those who were admitted at ward, continuing care process (step 4 to 7) was performed using the discharge care plan. The multidisciplinary team participated and patients were holistically reassessed. A period of 14-21 days of admission was expected due to the patient's right of treatment and support from the government services in social unrest. The discharge team (consists of 3-4 nurses), assigned in advance, was allocated depending on the shift work on that day. Each patient was taken care of by one of those four nurses who were assigned (alternate function if one of them was unavailable). Head nurses reflected that "this enabled nurses in the ward to work more flexibly under the system developed and reduce the problem of follow up and increase understanding of the patient's need and problems before discharge instead to leaving a patient without doing anything". The documentation was also attached to the patient's chart. However, the 9 steps in the care process may not be completed if the patient was discharged earlier or short stay as a result of minor injury. The continuing care team suggested of revising the care process by separating the care process to use for short-stay patients ( 3 days) and long-stay patients (more than 3 days).

Some problems and suggestions from participants were stated for further revision of the model (Table 1).

\section{Evaluation of the care outcomes}

Upon implementation of the model, 20 patients and 10 family caregivers were approached. The patient subjects primarily were older adults $(\mathrm{n}=11,55 \%)$, married ( $\mathrm{n}=19,95 \%)$, Muslim $(\mathrm{n}=13,65 \%)$, and educated at lower than elementary school $(n=14,70 \%)$. Before and after injury, subjects were primarily employed $(n=18,90 \%)$ and earned less than 10,000 baht per month $(n=13,65 \%)$ and all received support from several sources for hospital care cost. Regarding the history of family lost from terrorism, all had experience for the first time and about half were injured from bomb or gun shot. In terms of frequency of terrorist events in the living area during the previous year, about half reported 1-2 occurrences per year and more than $70 \%$ of the subjects had been injured for the first time. Duration of injury until present ranged from 1 day to 6 months and they had no history of disability before. The majority of subjects evaluated their own health as $\operatorname{good}(\mathrm{n}=16,80 \%)$.

Ten family caregivers were female aged between 20 and 60 years. More than half $(60 \%)$ were wives, the rest were parents; $70 \%$ were Buddhist and $30 \%$ were Muslim who had education at lower than secondary school (70\%). All earned income over 10,000 baht per month but 9 of them reported that this was adequate only for daily living. Most of them had at least one child or elderly to take care of.

During evaluation phase, intermediate care outcomes were measured using the questionnaire. Satisfaction with the care process was evaluated by trauma care team, patients and family caregivers. Self care ability and quality of life among 20 patients as well as ability to care and quality of life among 10 family caregivers were evaluated before discharge. Based on analysis of quantitative data, it was shown that

1. To ensure readiness to discharge, patients'self care ability and families'ability to care, measured before discharge, should achieve at least $80 \%$ of all knowledge and skill of both patients and family caregivers. The ability to care checklist related to patient's symptoms was used to evaluate the ability to assess and manage symptoms or perform some caring tasks as necessary eg. tube feeding. Family caregivers reported they were able to take care of the patients as needed following daily activities according to the educational plan. In case of mild and moderate injuries, most patients were encouraged to take care themselves with partially assistance from caregivers.

Self care was measured before discharge. Some activities can be performed without any change from prior to injury, which means that their self care remained normal such as being able to walk up and down on the ladder (first to the third floor) and take a bath or dress by themselves. Most of them reported that they were able to work less than expected (90\%) and reported emotional disturbances (60\%). After trauma, patients also reported a high impact on social activity (85\%), and pain was also reported as disturbing their daily activity. 
Page 6 of 8

After discharge, only 10 patients were followed up and reported that they were satisfied with the care process both in hospitalization and after discharge. Wound care and hygiene care were the most common skills performed at home. The least satisfaction was about the home visits by nurses, which for some reasons were not performed as scheduled. The main reason was related to personal safety and being unable to visit or follow up at that period. However, patients were visited by the community volunteers who were part of discharge care team.

\begin{tabular}{|c|c|}
\hline Problems & Suggestions \\
\hline $\begin{array}{l}\text { Duration in hospital was short } \\
\text { due to mild injury and some } \\
\text { patients required readmission } \\
\text { only because of their right to } \\
\text { receive pay from the government }\end{array}$ & $\begin{array}{l}\text { - Assess the need of hospitalization and estimate length of stay, classify the group for earlier discharge } \\
\text {-Explain and inform patient's service after discharge for continuing support by coordinating with the community health care team } \\
\text { and volunteer who provides care at home. } \\
\text { - Information about patient's and family's right to receive financial support must be given clear at the beginning to reduce personal } \\
\text { and organizational conflicts ( } 20 \text { and } 21 \text { days in hospital were very different in terms of financial support). Patient must be actively } \\
\text { involved in decision making and participated in the multidisciplinary team. } \\
\text { - Assign the job, trained volunteers from Deep South Coordination Center were allowed to visit patient at hospital and take an } \\
\text { important role in terms of providing clear information about the condition of financial support and patient's right. } \\
\text { - Summarize the record in the system under the refer in/out both for admission and referral to other hospitals }\end{array}$ \\
\hline Unable to follow the 9 steps & $\begin{array}{l}\text { - Nurses initially were unhappy to use the } 9 \text { steps as they found them to complex and separate from their routine work. The care } \\
\text { team then integrated those functions into the routine using checklist form in the care map. }\end{array}$ \\
\hline $\begin{array}{l}\text { lack of statement of occupational } \\
\text { therapist and physical therapist } \\
\text { role in the } 9 \text { steps }\end{array}$ & $\begin{array}{l}\text { - Add the role of occupational therapist in the care map for follow up in cases who had a disability score }>3 \\
\text {-Add activities performed by physical therapist both at hospital and home during follow up and include in the home health care } \\
\text { team }\end{array}$ \\
\hline $\begin{array}{l}\text { Special care and concerns to a } \\
\text { specific groups eg. Children }\end{array}$ & $\begin{array}{l}\text { - Add the guideline to follow up and improve the child development (and the follow up family impact). } \\
\text { - Identify clearly about the role of home health care team to visit patient before discharge and work collaboratively with other } \\
\text { community organizations. }\end{array}$ \\
\hline
\end{tabular}

Table 1 : Problems and suggestions from participants for model development.

2. Satisfaction was also measured at discharge to evaluate the care process twice at hospital and at home after one month discharge. In order to collect this satisfaction data after patient was discharged, the discharge planner communicated with the home health care team for follow up. This was performed under the care process which stated the role and function of each team to be able to follow up as planned.

Nurse' satisfaction was also measured at the end of the project. It was found that 14 in 20 nurses who responded were satisfied with the documentation in the model such as discharge nurse note and care process checklist form with the average score of 8.5 (from a maximum score of 10). Nurses indicated that this model was useful to implement and enhance holistic nursing care. They identified the importance of the multidisciplinary team in the model and enhanced the trauma care continuum process. Nurses were the care managers and able to function independently. However, although the care model was of benefit, the care process in this model was not appropriate for patients who had a short stay in hospital.

The questionnaires used for assessment of patient's self care and family caregiver's ability to care were revealed a mean of satisfaction at 5.5 (from a maximum score of 10). Due to many items and long pages to be assessed with a difficult language to understand, some nurses felt less satisfied and suggested a revision of the form. The family's ability to care assessment form was not appropriate and not need in the family of patients with only minor injury. However, both patient's self care and family caregiver's ability to care for patients from the checklist form were increased in every item before discharge.

3. Quality of life. As described in Table 2, quality of life was measured using SF-36. Overall, subjective data on health status reported by patients was at a moderate level $(M=50, S D=8.57)$. If compared with the last year, current health status was at a moderate level $(M=25, S D=14.43)$. Of 20 subjects, it was found that overall QOL was at a moderate level $(\mathrm{M}=43.89, \mathrm{SD}=12.61)$. Physical domain and psychological domain of QOL were both at a moderate level $(\mathrm{M}=52.64, \mathrm{SD}=13.26$ and $\mathrm{M}=54.03, \mathrm{SD}=10.13$ respectively $)$. The overall QOL in 10 subjects of caregivers who were assessed before discharge was at a high level $(\mathrm{M}=70.01, \mathrm{SD}=12.95)$. Physical domain and psychological domain of QOL were both at a high level $(\mathrm{M}=77.22$, $\mathrm{SD}=8.53$ and $\mathrm{M}=68.05 \mathrm{SD}=7.20$ ) respectively. However, health status was perceived at a moderate level if compared to the previous year (Table 2).

\begin{tabular}{|l|l|l|l|l|}
\hline QOL & $\begin{array}{l}\text { Patients } \\
(\mathbf{n = 2 0 )}\end{array}$ & Level & Caregivers & Level \\
\hline & $\mathbf{M}(\mathbf{S D})$ & & $\mathbf{( n = 1 0 )}$ & \\
\hline Total & $43.89(12.61)$ & moderate & $\begin{array}{l}70.01 \\
(12.95)\end{array}$ & high \\
\hline Physical domain & $52.64(13.26)$ & moderate & $77.22(8.53)$ & high \\
\hline Psychological domain & $54.03(10.13)$ & moderate & $68.05(7.20)$ & high \\
\hline $\begin{array}{l}\text { Compare health with last } \\
\text { year }\end{array}$ & $25.00(14.43)$ & low & $\begin{array}{l}45.00 \\
(10.54)\end{array}$ & $\begin{array}{l}\text { moderat } \\
\text { e }\end{array}$ \\
\hline
\end{tabular}

Table 2 : Mean scores of QOL of patients and caregivers on discharge day.

As indicated in Table 3, only 10 subjects could be followed up after discharge due to safety issues. It was found that overall QOL was at a moderate level $(\mathrm{M}=64.93, \mathrm{SD}=.53)$. Physical domain and psychological domain of QOL were at moderate $(\mathrm{M}=77.42, \mathrm{SD}=1.58)$ and high level $(M=67.36, S D=0.00)$ respectively. When they were asked to compare 
health status with the previous year, current health status was perceived as being at a moderate level $(M=50, S D=0.00)$.

\begin{tabular}{|l|l|l|}
\hline QOL & Patients M (SD) & Level \\
\hline Total & $64.93(.53)$ & moderate \\
\hline Physical domain & $77.42(1.58)$ & moderate \\
\hline Psychological domain & $67.36(0.00)$ & high \\
\hline Compare health with last year & $50.00(0.00)$ & moderate \\
\hline
\end{tabular}

Table 3 : Mean scores of QOL of patients after discharge $(n=10)$.

\section{Discussion}

Process of the model development : Several advantages of PAR were observed such as fostering full participation of the care team in the research process and facilitating participants to solve their problems simultaneously including creating and strengthening the community support network to enhance self care and ability to care among patient and family caregivers. Although some complications could not be evaluated due to short time for follow up in the study, this model created the mutual relationship between patient, family, community volunteer and nurses after discharge within a social unrest context. The strategies used for this model were teamwork involvement, care coordination, and staff education. Through PAR, critical elements of team involvement with full participation resulting to the successful of model implementation [8,9]. This methodology is consistent with others used to conduct PAR in the Thai context such as development of nursing case management model for patients with myocardial infarction [10] and development a model of care for enhancing well being of people with paraplegia in community [11]. The previous studies also reported the benefit of the PAR process in building the capacity of health care staff and nursing program for specific groups. However, this study has included a multidisciplinary team in a surgical unit of both a primary and secondary care hospital and nongovernment organization in the development of model that is acceptable to the participants working in unrest areas and which has potential for sustainability.

Model implementation and outcomes : The findings suggested that implementation of the model could lead to changes in care outcomes at some levels. The PAR process can raise awareness of nurses and care team who function as discharge planner, ward nurses and allied health personnel involved in preparedness of trauma patients and caregivers before discharge. Increased information and psychosocial support given to trauma patients and caregivers by nurses and allied health through the discharge plan were found. In order to raise their awareness and knowledge of providing continuing care, several workshops and team meetings were essential for nurses and allied health personnel to understand their role and function in the care process. Although the improvements in the care process seem to have made little difference in patient outcomes, nurses and allied health personnel were satisfied with the model after implementation, compared to the beginning of the project.

Although the satisfaction score related to assessment of patients' self care and family caregivers' ability to care was not as high as expected, nurses observed and reflected on their increased functions in health education through discharge planning and monitoring their activities for continuing care. Group discussion and participant observation in the workshops also assist their attention to improving both patient and caregiver's knowledge and skill by health education and follow up until discharge.

In general, patients' quality of life (QoL) is recognized as a critical indicator of their outcome including following trauma. Additionally, a previous study of QoL among trauma survivors from unrest situation has shown that the mean total and the mean of each dimension of QoL score of trauma survivors in the unrest area of the southernmost provinces were at a moderate level [12]. Quality of life was then assessed, which aimed to reflect a particular patient's outcome as a result of model implementation. Due to the short time of evaluation and some limitation for follow up discharge, changes at the QoL level may not have been high after model implementation (see Table 1 and 2). However, the psychological domain of QoL alone was found to be improved, partly because of involvement of a healing team and continuing support from the multidisciplinary team according to the follow up discharge in the model development. In addition, the government policy of providing momentary support could help many trauma survivors receive some level of psychological support after discharge compared to those who did not receive any such aid, which is similar to the findings of previous studies $[8,12]$.

\section{Limitations}

Some limitations must be taken into consideration when interpreting the findings. First, the model was only developed for one general hospital located in social unrest, southern Thailand which could be limited for generalizability. Secondly, the study results were only a short term and could not reflect the sustainability.

\section{Conclusions and recommendations}

The trauma-based continuing care model can serve as a potential model for nurses or health care professionals for enhancing quality of trauma nursing care process and outcomes. Three main components are important to be included with appropriate strategies: 1) preparing the multidisciplinary health care team through training and education, 2) organizing the system through coordination and 3) collaborating with community support network using teamwork. However, given the study limitations, future research needs to examine the long-term outcomes of this model implementation and include participants from other hospitals to maximize findings. QoL and self-care ability among both patients and family caregivers must be obtained after discharge for outcome evaluation.

\section{Acknowledgement}

The authors gratefully acknowledge to all participants who were active involved in the care model. Special thanks are also extended to the Higher Education Research Promotion and the National Research University Project of Thailand, Office of the Higher Education Commission, for funding. In addition, we wish to express our gratitude to Dr. Alan Geater for editing this manuscript.

\section{References}

1. Eastman AB, Schuab CW, Annest JL, Aprahamian C, Beachley M, Browner B, et al (1997). Position paer on trauma care systems. J Trauma, 32: 127-129.

2. American Trauma Society. Trauma system agenda for the future (2004) US Department of Transportation: National Highway Traffic Safety Administration 
Citation: Songwathana P, Sae-Sia W, Kitrungrote L, Manoonya B (2014) Development of a Trauma-based Continuing Care Model for Enhancing Care Outcomes in Social Unrest Area: A Case Study. J Nurs Care 3: 204. doi:10.4172/2167-1168.1000204

Page 8 of 8

3. Diane EH, Marcelline RH. (2007)Discharge Planning, Transitional Care Coordination of Care, and Continuity of Care: Clarifying Concepts and Terms from the Hospital Perspective Home. Health Care Services Quart 26:3-19

4. Heslop L, Elsom S, Parker N (2000) Improving continuity of care across psychiatric and emergency services: combining patient data within a participatory action research framework. J Adv Nurs 31: 135-143.

5. Bellman L, Bywood C, Dale S (2003) Advancing working and learning through critical action research: creativity and constraints. Nurse Educ Pract 3: 186-194.

6. Biem HJ, Hadjistavropoulos H, Morgan D, Biem HB, Pong RW (2003) Breaks in continuity of care and the rural senior transferred for medical care under regionalisation. Int J Integr Care 3: e03.

7. Kemimis S, Mctaggart R (2000) Participatory action research. In Denzin, NK., Lincohn, YS. (eds). Qualitative Research. Thousand Oaks: Sage publications 567-605.
8. Songwathana P, Watanasiriwanich W, Kitrungrote L (2013) Holistic selfcare for rehabilitation experienced by thai buddhist trauma patients in areas of political and social unrest. J Trauma Nurs 20: 203-207.

9. Wilson-Thomas, L. Applying critical social theory in nursing education to bridge the gap between theory, research and practice. J Adv Nurs, 1995; 21: 558-75.

10. Stringer ET. Action research in health (1999) Upper Saddle River (NJ): Pearson Education

11. Khupantavee N, Songwathana P, Chuaprapaisilp A (2008) The meaning of well-being: the experience of Thai people with paraplegia" Songklanagarind J 26:1-10

12. Phengsakul M, Koowantawee N, Songwathana P (2013) Quality of life of disabled and non-disabled Trauma Survivors in Thai Unrest Area of Southernmost Provinces, Paper presentation at 24th International Nursing Research Congress, Prague, Czech Republic. 